\title{
Effect of Compaction Temperature on Sinterability of Magnesium and Aluminum Powder Mixtures by Warm Compaction Method*
}

\author{
Taku Iwaoka ${ }^{1}$ and Mitsuru Nakamura ${ }^{2}$ \\ ${ }^{1}$ Tokyo Metropolitan Industrial Technology Research Institute, Tokyo 115-8586, Japan \\ ${ }^{2}$ Faculty of Engineering, Iwate University, Morioka 020-8551, Japan
}

\begin{abstract}
An oxide film is easily formed on the surface of magnesium and aluminum powders due to the high chemical reactivity of these metals. The sinterability of these powders is extremely poor for conventional powder metallurgy. At present, the behavior of the warm compaction method, which has been done using iron powder, is practically very interesting, because high density and strongly sintered materials are efficiently obtained. However, there are only a few reports on the sinterability of magnesium and aluminum powder mixtures by this method. In this study, to consider the sinterability of such mixtures, we examined the effect of the compaction temperature. The compacts that consist of these mixtures were consolidated by the warm compaction method, which was conducted in the temperature range from 301 to $423 \mathrm{~K}$. The compacts were sintered in an argon atmosphere. As a result, the transverse rupture strength for the warm compaction was from 20 to $30 \mathrm{MPa}$ higher than for the cold compaction. The increasing compaction temperature causes sufficient contact between the powder particles, and at the same time, plastic deformation of the powder particles readily occurs. This behavior induced by the warm compaction method would lead to a break down of the oxide films. As a result, sufficient bonding between the powder particles occurred, and the transverse rupture strength increased. [doi:10.2320/matertrans.L-MZ201129]
\end{abstract}

(Received September 29, 2010; Accepted March 1, 2011; Published April 20, 2011)

Keywords: warm compaction, sinterability, magnesium-aluminum eutectic, real contact

\section{Introduction}

For several years, many papers on the warm compaction of metal powders have been published. Technical interest and discussions were stimulated by the warm compacting of ferrous powders. ${ }^{1)}$ The warm compaction method is a promising way to efficiently increase the green density and the strength of the sintered compact. There is a possibility that better characteristics comparable to conventional double pressing and double sintering processes are readily accomplished by elevating the compacting temperature. ${ }^{1,2)}$ This method also results in the formation of more real contacts on the metal powders during compacting. Consequently, the mechanical properties of the powder metallurgical materials are improved. The possibility of using warm compaction for non-ferrous powders has recently been studied, although magnesium powders have been only slightly examined.

With the ongoing trend in the weight savings of transportation equipment, the application of light alloys is increasing. The magnesium alloys are the lightest of the practicable metallic materials, which are regarded as environmentally-friendly materials. Industrially useful new magnesium alloys may be created by powder metallurgy. However, the magnesium particles have an oxide film on its surface. Therefore, we expected that the sintering progress of its powder would be inhibited. In addition, as a consequence of the hcp structure, magnesium exhibits only a limited ductility at ambient temperature. ${ }^{3)}$ At room temperature, the compressibility of the magnesium powder decreases due to this poor workability. In order to sufficiently compact and sinter the magnesium powders, vacuum degassing of the powder and special consolidation processes, such as hot

*The Paper Contains Partial Overlap with the ICAA12 Proceedings by USB under the Permission of the Editorial Committee. pressing or forging, must be used. Clearly, these processes are not cost effective for high-volume production.

Therefore, we focused on the mixing of an aluminum powder with magnesium powder for warm compaction. Some metallographic evidence and mechanical properties of these powder metallurgical material mixtures were measured with regard to their compacting and sintering. The influence of the compaction temperature and adding aluminum powder on the sinterability of these materials was investigated. This paper presents the application of the warm compaction method on the compacting and sintering behavior of the magnesium and aluminum powder mixtures.

\section{Experimental Procedure}

Magnesium powder (99.8\% purity, -100 mesh, supplied by Chuo-Kosan Co., Ltd.) and aluminum powder $(99.7 \%$ purity, -100 mesh, supplied by Yamaishi Metal Co., Ltd.) were used in the present study. Each powder was characterized by scanning electron microscopy (SEM). The aluminum and magnesium powder mixtures were prepared by adding 12 mass $\%$ aluminum powder to the magnesium powder. The powder mixtures were mixed for $0.6 \mathrm{ks}$. For comparison purposes, a pure magnesium powder was also prepared.

Figure 1 shows a schematic illustration of the die assembly used for the warm compaction method. To heat the powder mixtures, the outside of the die was equipped with a heater. The compaction temperature was controlled by the temperature of the powder mixtures packed into the die. The powder mixtures were consolidated through uniaxial compacting in a floating die which can attain more homogeneous compacts than the fixed die. The graphite-organic binder type was used as the compacting lubricant. About $3 \mathrm{~g}$ powder mixtures were packed by tapping the die having the inside diameter 


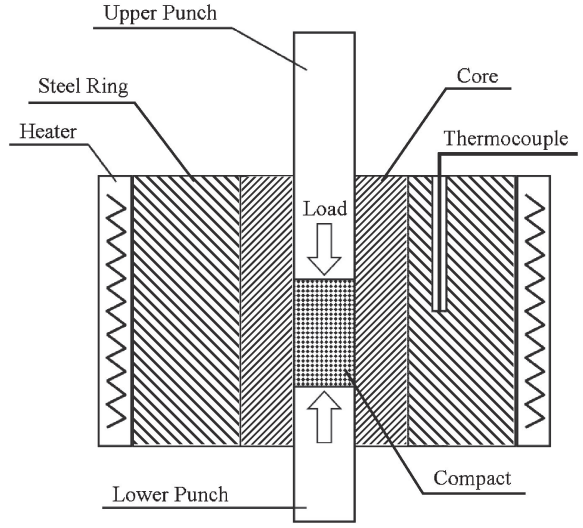

Fig. 1 Schematic illustration of the die assembly used for the warm compaction method.

of $10 \mathrm{~mm}$. The compacting pressure was $489 \mathrm{MPa}$ and the compaction temperatures ranged from 301 to $423 \mathrm{~K}$. In order to evaluate the compacts, the porosity, the ejection force and the spring-back were examined. The pores of the compacts were observed by optical microscope (OM). The resulting images were binarized and analyzed using standard image analysis software to measure the porosity degree. The ejection force was obtained by dividing the maximum load by the lateral area of the compacts. The spring-back relative to the die is considered in compacting and is defined as:

$$
\text { Spring-back }(\%)=(d-D) / D \times 100
$$

where $d$ is diameter of the green compact, $D$ is diameter of the die cavity.

Each of the powder mixture compacts was sintered at from 673 to $733 \mathrm{~K}$ for $3.6 \mathrm{ks}$ in an argon atmosphere. The heating and cooling rates were 0.19 and $0.37 \mathrm{~K} / \mathrm{s}$, respectively. The microstructure of the sintered compacts was examined using an OM, SEM and energy dispersive X-ray spectrometry (EDX). The compressive strength and the transverse rupture strength of the sintered compacts were then evaluated using a universal test machine (Autograph, AG-10TD, Shimazu). Each of the tests was performed at a cross-head velocity of $1.7 \times 10^{-5} \mathrm{~m} / \mathrm{s}$. The specimens of $10 \mathrm{~mm}$ diameter and $14.7 \mathrm{~mm}$ height were examined until their destruction. After strength testing, the fracture surfaces of ruptured specimen were examined using a SEM.

\section{Experimental Results and Discussion}

\subsection{Compressibility and compactibility}

Figure 2 shows the morphology of the magnesium and aluminum powders. The mean particle sizes of these powders were 140 and $122 \mu \mathrm{m}$, respectively. Figure 3 shows the pore distribution of a longitudinal section in the green compacts. Lamination cracks indicated by arrows were observed in pure magnesium green compact during cold compaction. This was not observed in other conditions. It was observed that the pores were almost homogeneously distributed under all conditions. The comparatively small pores mostly disappeared at the compaction temperature of about $423 \mathrm{~K}$. The porosity of the green compacts decreased with increasing compaction temperature. The plastic deformation on the surface of the powder particles occurred because of the activation of the magnesium's non-basal slip systems. Also, the addition of aluminum powder slightly induced a decrease in the porosity because the deformability of aluminum is much better than that of magnesium. This shows that the disappearance of the pores occurred because of a sufficient contact between the powder particles. Figure 4 shows the relation between the ejection stress and spring-back in the
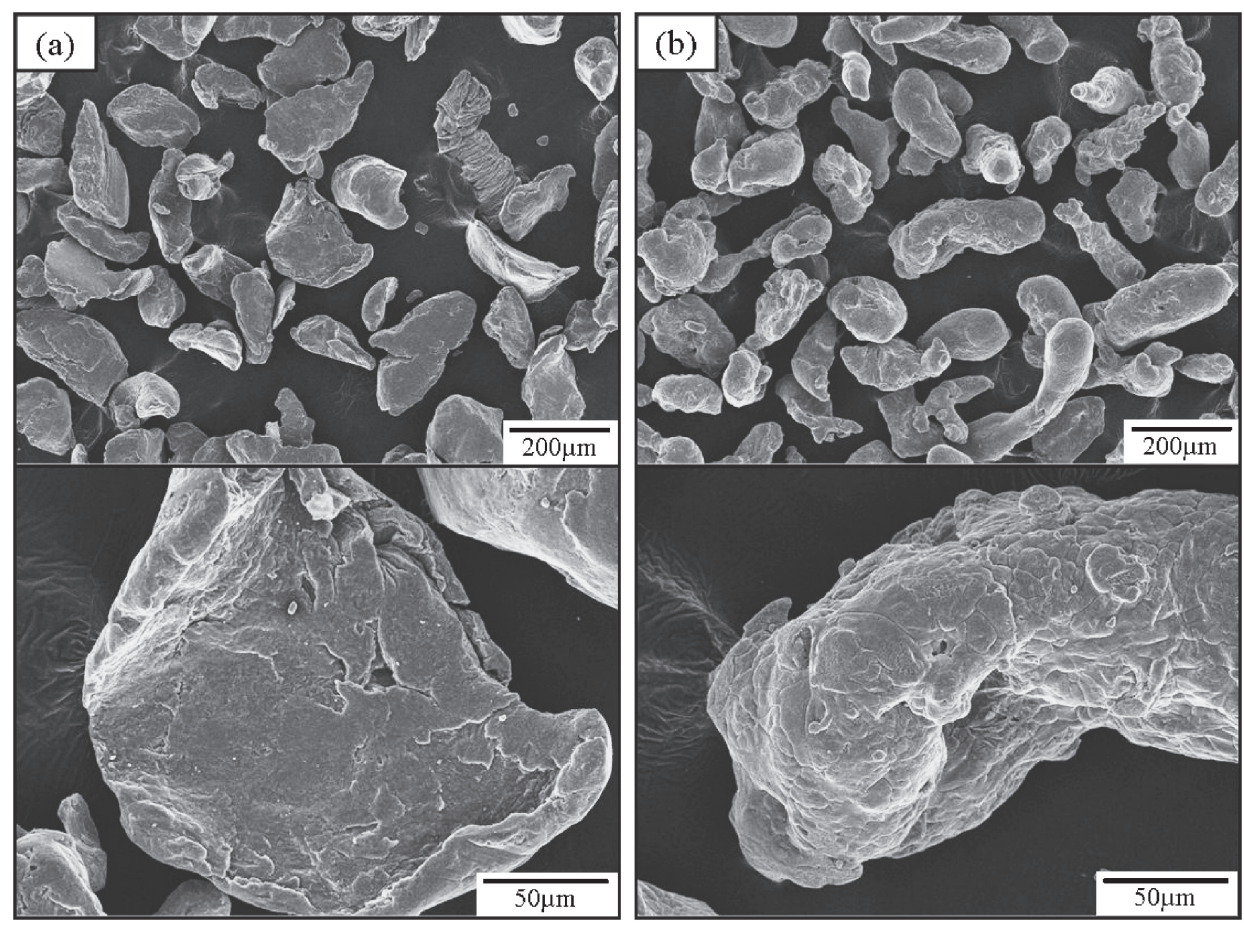

Fig. 2 SEM images showing the morphology of (a) magnesium and (b) aluminum powders. 


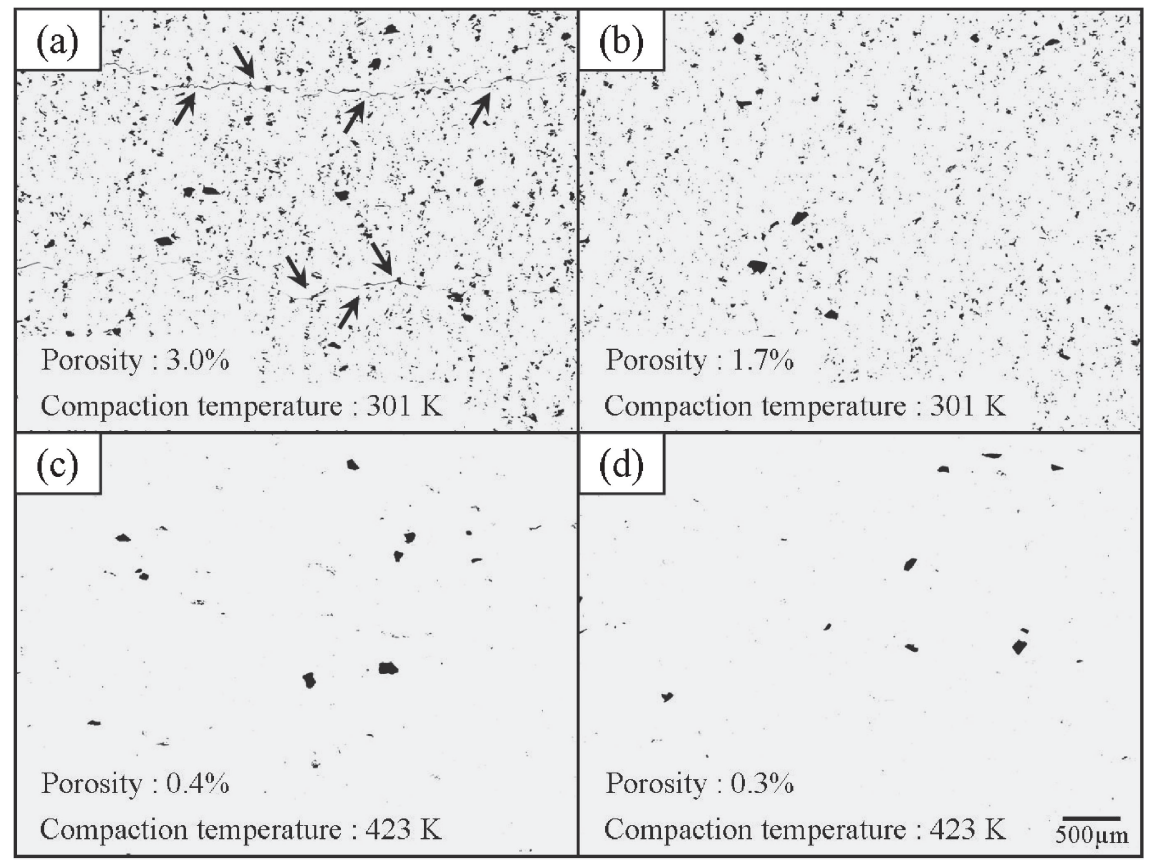

Fig. 3 The pore distribution of a longitudinal section in the green compacts: (a) cold-compacted pure magnesium, (b) cold-compacted $\mathrm{Mg}-12 \% \mathrm{Al}$, (c) warm-compacted pure magnesium, (d) warm-compacted Mg-12\% Al (compacted pressure: $489 \mathrm{MPa}$ ).

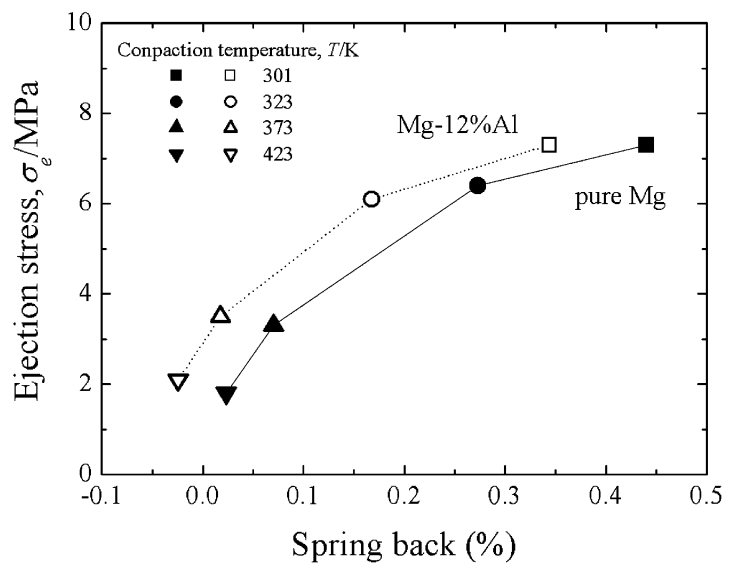

Fig. 4 Relation between ejection stress, $\sigma_{\mathrm{e}}$ and spring back of the green compacts that were processed at $489 \mathrm{MPa}$.

green compacts. The addition of aluminum powder decreased the spring-back. The behavior of the pure magnesium powder with respect to the ejection stress was similar to that of the $\mathrm{Mg}-12 \% \mathrm{Al}$ powder mixtures. The warm compaction also resulted in a lower expansion in the radial direction of the green compacts. The friction force acting between the die wall and the surface of the green compacts decreased because the radial elasticity stress is low. As a result, the ejection stress of the green compacts decreased. The consequence was that the compressibility and compactibility of these powder mixtures improved.

\subsection{Sinterability}

Figure 5 shows the microstructure of the $\mathrm{Mg}-12 \% \mathrm{Al}$ sintered compacts. It was observed that the aluminum powders were almost homogeneously distributed under both conditions. The disappearance of the spaces between powder particles was confirmed in Fig. 5(b). The powder particles were in mutual contact because of the enough plastic deformation due to the warm compaction. The apparent contact between the powder particles changes into a real contact. Figure 6 shows the relation between the compressive strength of the sintered compacts and the compaction temperature. The compressive strength increased with increasing compaction temperature. The compressive strength remarkably increased at $323 \mathrm{~K}$, and it slightly changed at $323 \mathrm{~K}$ or higher.

Figure 7 shows the relation between the transverse rupture strength and sintering temperature in the pure $\mathrm{Mg}$ and $\mathrm{Mg}$ $12 \% \mathrm{Al}$ sintered compacts. The transverse rupture strength of sintered specimens through both cold and warm compactions increased with the increasing sintering temperature. This strength due to the warm compaction was from 20 to $30 \mathrm{MPa}$ higher than that due to the cold compaction. Figure 8 shows the microstructures of the cross section of fractured specimens in $\mathrm{Mg}-12 \% \mathrm{Al}$ sintered compacts that were sintered at $733 \mathrm{~K}$ for $3.6 \mathrm{ks}$. The upper side is neighborhood of fractured surfaces (Fig. 8, Fracture). And, the lower side is undeformed regions (Fig. 8, Center). The $\mathrm{Mg}$-Al eutectic structures were observed in sintered compacts by both cold and warm compacted specimens (Fig. 8, Center). The elevated sintering temperature promoted the $\mathrm{Mg}$ - $\mathrm{Al}$ eutectic reaction. The transverse rupture strength of the sintered compacts made by cold and warm compactions in Fig. 7 was influenced by the $\mathrm{Mg}$-Al eutectic structure. Figures 8(a) and $8(\mathrm{~b})$ respectively shows sintered structures of the cold and warm compacted specimens. Weak bonding between powder particles due to cold compaction caused the fracture at the boundaries (Fig. 8(a), Fracture). In contrast, it was shown that the $\mathrm{Mg}$-Al eutectic breaking frequently occurred near fracture surface (Fig. 8(b), Fracture). Therefore, it was found that the bonding between powder particles due to 

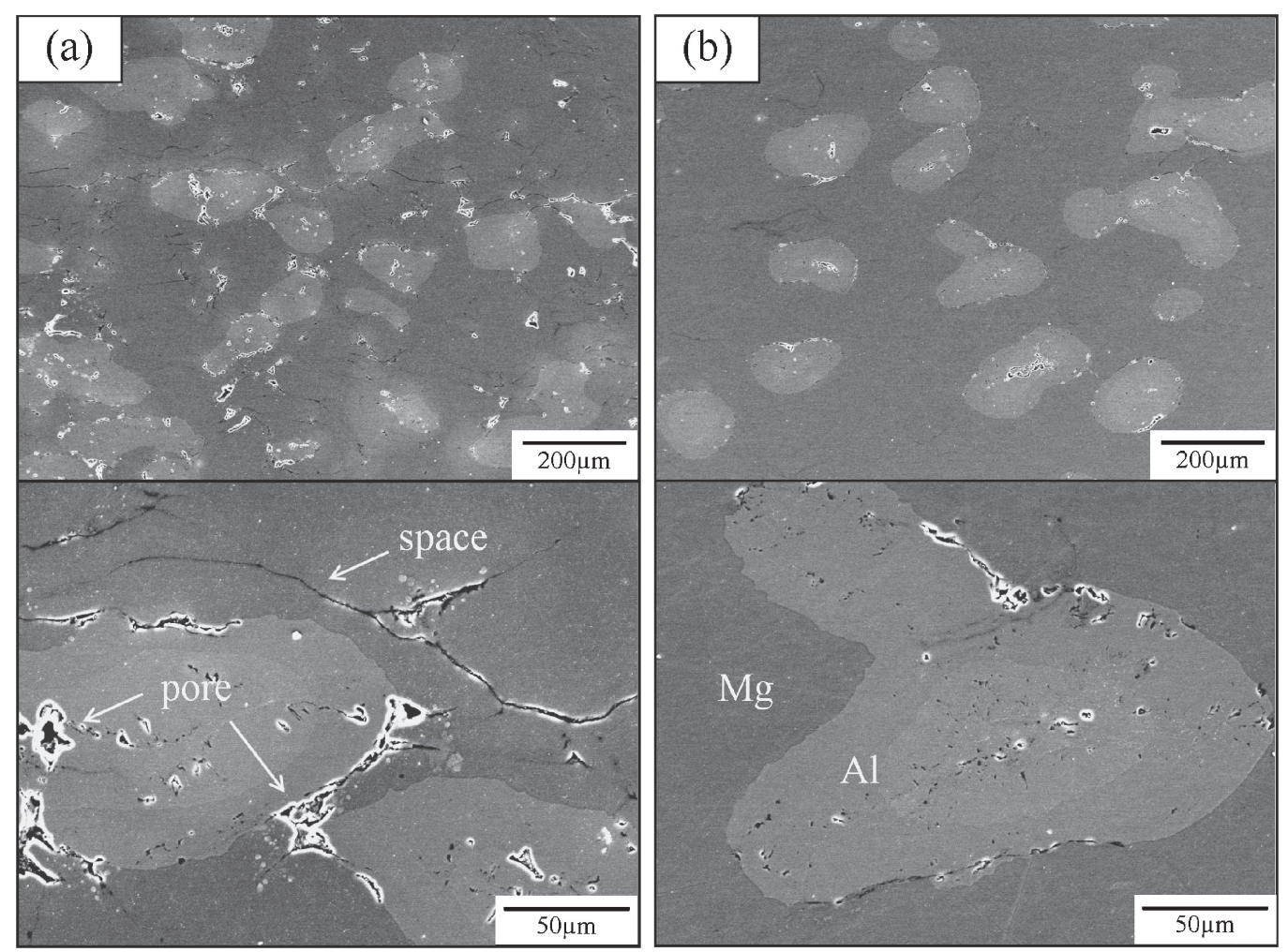

Fig. 5 SEM images microstructure of sintered compacts sintered at $673 \mathrm{~K}$ for $3.6 \mathrm{ks}$ : (a) cold and (b) warm compacted powder mixtures.

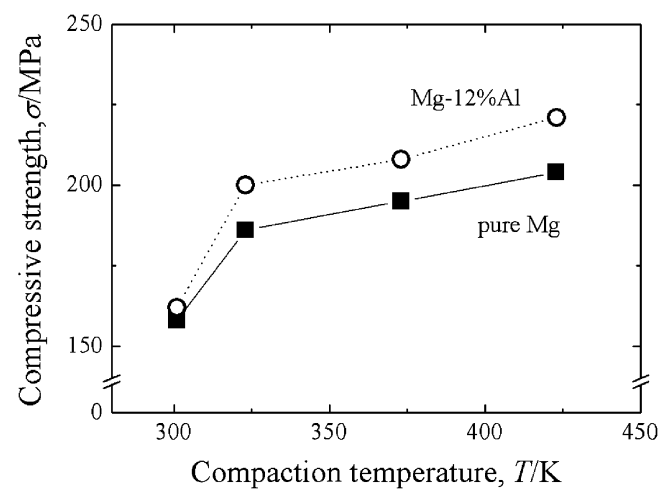

Fig. 6 Relation between compressive strength, $\sigma$ and compaction temperature, $T$ of the sintered compacts sintered at 673 for $3.6 \mathrm{ks}$. (compacting pressure: $489 \mathrm{MPa}$ )

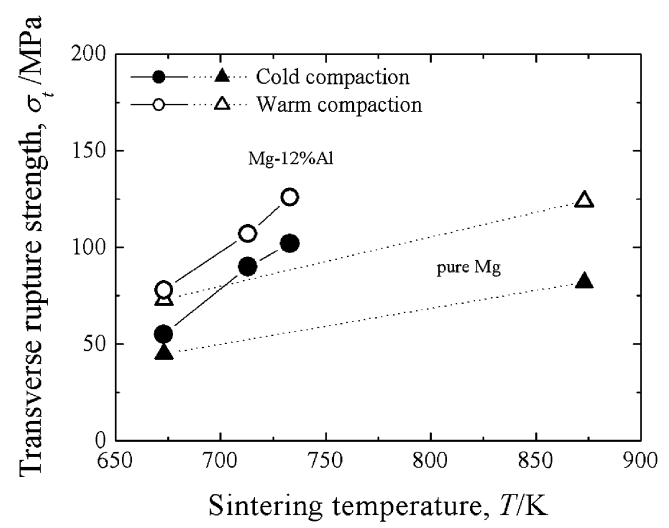

Fig. 7 Relation between transverse rupture strength, $\sigma_{t}$ and sintering temperature, $T$ in pure $\mathrm{Mg}$ and $\mathrm{Mg}-12 \% \mathrm{Al}$ sintered compacts. (compacting pressure: $489 \mathrm{MPa}$ ) warm compaction was stronger than that due to cold compaction. SEM image of the fractured surface of the transverse ruptured specimen is shown in Fig. 9. Not only the fracture of partial bonding between powder particles but also the fracture of powder boundary that shows the unbonding was confirmed. The bonding was caused by the real contact between the powder particles. The contact was promoted by the warm compaction before sintering, whereas the contacting areas after sintering were not very large. However, the progress of sintering magnesium powders is recognized when compared to conventional sintering, because the sinterability of powders is significantly influenced by the contact conditions between the powder particles. The oxide films partially broke because the real contact area between the powder particles increased due to the warm compaction. As a result, sufficient bonding between powder particles occurred, and the transverse rupture strength increased.

\section{Conclusion}

In this study, the effects of the compaction temperature on the sinterability of magnesium and aluminum powder mixtures were investigated using a die equipped with a heater. The microstructure and strength of the sintered compacts with added 12 mass\% aluminum powders were evaluated by SEM-EDS and a universal testing machine, respectively. The obtained results are summarized as follows:

(1) The compressibility and compactibility of the magnesium and aluminum powder mixtures improved with increasing compaction temperature and addition of aluminum powder. 

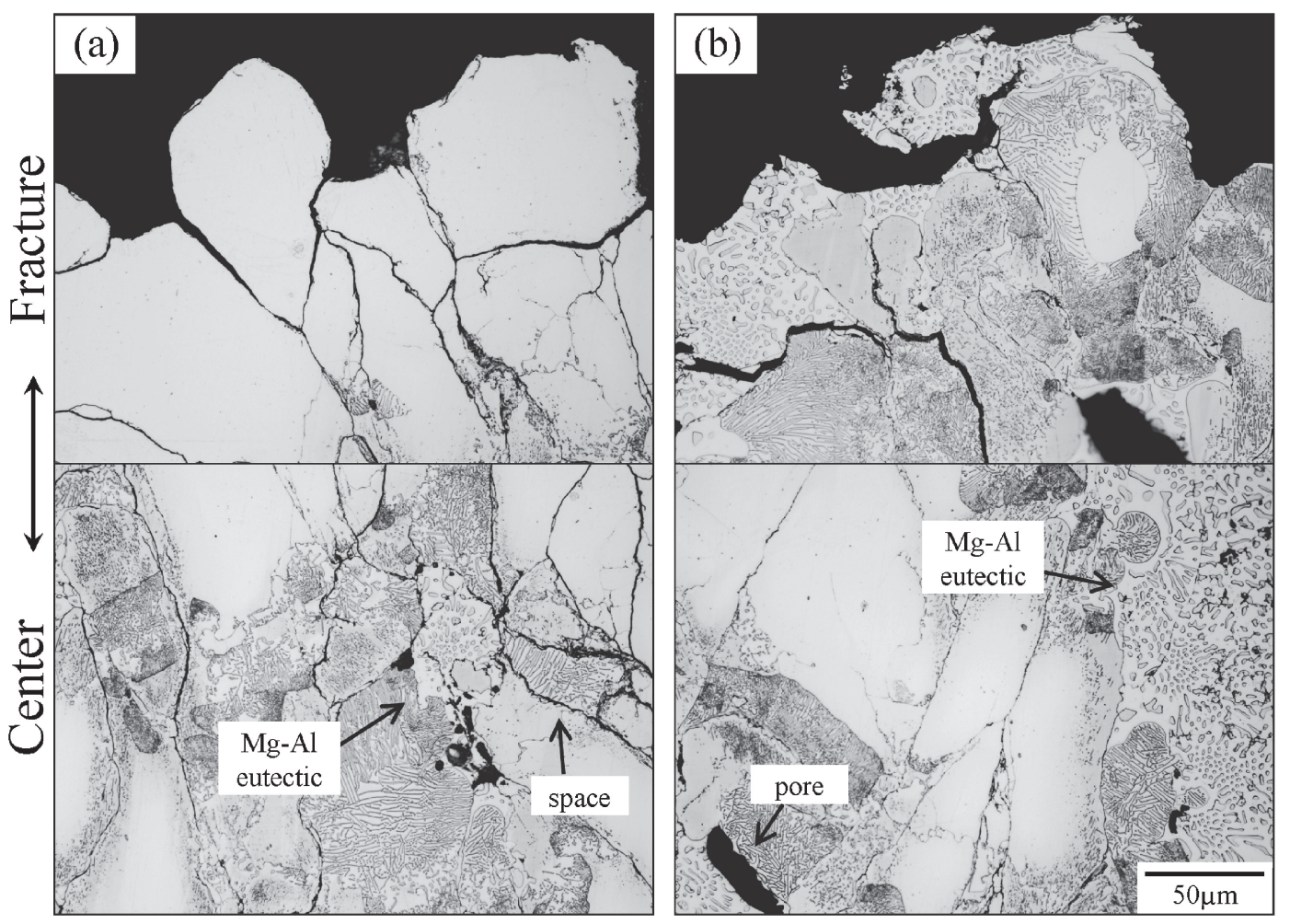

Fig. 8 Microstructures of the cross section of fractured specimens in $\mathrm{Mg}-12 \% \mathrm{Al}$ sintered compacts sintered at $733 \mathrm{~K}$ for $3.6 \mathrm{ks}$ : (a) cold and (b) warm compacted powder mixtures.

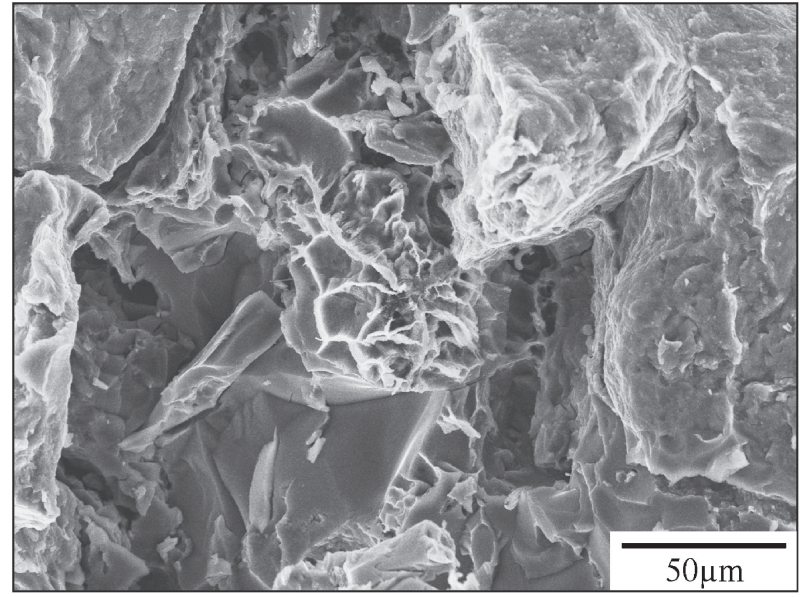

Fig. 9 SEM image of the fractured surface of the transverse ruptured specimen sintered at $713 \mathrm{~K}$ for $3.6 \mathrm{ks}$ by warm compaction.

(2) The addition of aluminum powders caused the $\mathrm{Mg}-\mathrm{Al}$ eutectic reaction at a moderate sintering temperature. And, the elevated compaction temperature caused the real contact between powder particles. The transverse rupture strength of the $\mathrm{Mg}-12 \% \mathrm{Al}$ sintered compacts made by warm compacted specimens was from 20 to
$30 \mathrm{MPa}$ higher than that by cold compacted specimens. This is because sufficient bonding between powder particles from the partial oxide film breakings and the eutectic structure formations occurred.

(3) The combined effect of the warm compaction and aluminum powder addition resulted in an increasing strength. This result clearly demonstrated that the warm compaction process not only influenced the compressibility and compactibility of the compacts, but also affected the sintering behavior.

(4) The strengthening of the sintered compacts is expected due to the eutectic reaction which is strictly controlled by the starting powder and sintering conditions. In conclusion, the experimental results presented in this paper showed that the warm compaction process might be a promising method for processing lightweight powder metallurgical materials.

\section{REFERENCES}

1) H. G. Rutz and F. G. Hanejko: Int. J. Powder Metall. 5 (1994) 117-133.

2) A. Simchi and G. Veltl: Powder Metall. 46 (2003) 159-164.

3) A. Yamashita, Z. Horita and T. G. Langdon: Mater. Sci. Eng. A 300 (2001) 142-147. 